\title{
LEADERSHIP STRATEGY IN MANAGING WORKPLACE DIVERSITY
}

\author{
Amuta Arumugam ${ }^{1}$, Dr.Ganesan Shanmugavelu,PhD ${ }^{2}$, \\ Dr.Yahya Osman, $\mathbf{P h D}^{3}$, Dr.Khairi Ariffin, $\mathbf{P h D}^{4}$, \\ Dr.M.Nadarajan Manickam,PhD ${ }^{5}$, Jagdave Singh Avtar Singh ${ }^{6}$ \\ ${ }^{1}$ Certified Counselor, Ipoh, Perak, Malaysia \\ ${ }^{2}$ Senior Lecturer, Institute of Teacher Education Ipoh Campus, Perak, Malaysia \\ ${ }^{3}$ Director, Institute of Teacher Education Ipoh Campus, Perak, Malaysia \\ ${ }^{4}$ Associate Professor, Sultan Idris Education University, Perak, Malaysia \\ ${ }^{5}$ Senior Lecturer, Institute of Teacher Education Keningau Campus, Sabah, Malaysia \\ ${ }^{6}$ Principal, Taman Melawati Secondary School, Selangor, Malaysia
}

Article DOI: https://doi.org/10.36713/epra8988

DOI No: 10.36713/epra8988

\begin{abstract}
Leadership is how all the possible dimensions of diversity are managing an organization develops an essential ingredient for any workplace that wants to build happier, more productive and more effective workplaces. Leadership sets the tone for the rest of the organization, recognizing and assessing cultural differences helps the organization to frame sound workforce management strategy and in developing positive workplace outcomes. The way leaders working in global arena have to take cultural differences and values into the main consideration while formulating an effective motivation and leadership strategy. Diversity carries out specific strategies to get leaders have initiated efforts that highlighting a conceptual paper concept and few challenges of workforce diversity. It needs to be the official set application of motivation, leadership practices and also discusses the real-life diversity management. The key area to look within the leadership team workplace diversity is a challenge for everyone, especially managers and business owners. This paper underlines a necessary step to ensure that diversity remains a core business value, even leadership contributes an idea to management policy makers for designing an oriented motivational and leadership strategy for managing a diversified workforce.
\end{abstract}

KEYWORDS : Leadership, Workplace, Diversity, Motivation, Competencies, Challenges,

\section{INTRODUCTION}

With such workforce diversity, it becomes important for organisations to put in place policies and practices to build an inclusive and pleasant workplace. An organisation is striving to create a workplace where everyone feels valued and respected inclusive workplace is one that appreciates differences amongst workers and works towards maximising their potential. This toolkit aims to help organisations to understand why managing workplace diversity is important, assess how the organisation is managing diversity, implement practices, policies to manage diversity and build an inclusive congruent workplace. The achievement and efficacy of the business depend upon the management policies, human resource development strategy, greater motivation, commitment of people, 
and optimization of all the resources willingness to manage diverse a workforce through effective human resource management strategies. The goal of this study is to reflect the readers about the significance dimensions while motivating and leading diversified workforce. Achieving an inclusive workplace that drives performance, innovation and productivity requires true benefits of a diverse concept include acceptance and respect, means understanding that each individual is unique, and recognizing individual differences. Leaders must foster workplace flexibility and be open to different ways of working for any adjustment each other and moving beyond simple tolerance to embracing and celebrating the rich dimensions of diversity contained within each individual. The diversity practices and equipping leaders with an immense source of opportunities, but it can also mean the opposite, a big threat.

Diversity is a managerial and a leadership approach in response to these trends and can help companies to effectively and efficiently manage their personnel diversity, especially, personnel made up of diverse and multifaceted people. Promoting workplace leadership is a process that takes place in many stages and on many levels. Managing diversity is one of the most important challenges faced by manager in their organizations to be oriented leadership. They provide a roadmap to foster diversity differ in terms of lifestyle, the choices available, perspectives, attitudes, value system, beliefs, behaviours, expectations, skills and experiences. These critical success factors provide areas of focus not just discriminatory practices, but they modify the nature and demands placed on leadership, management and bring into prominence the concept of diversity. The priorities and actions will track what manner or how leaders are able to invest in the concept of diversity will impact not just on work issues, but sensitivity to the customer's needs, legal compliance, business ethical issues, profitability and even social cohesion.

Workplace diversity, leadership is a strategic process to manage a workplace, including the fight against stereotypes, prejudice and all kinds of discrimination due to the individual perceptions and assumptions. It is related to manner to maximize the benefit and minimize barriers of different opinions, behaviour and attitudes of human beings within a company. It explores workplace diversity, leadership is a strategy that is intended to foster and maintain a positive workplace environment. Usually initiated by professional department heads and supervisors, an effective diversity, leadership program will promote recognition and respect for the individual differences found among a group of employees. It gives working definitions of key terms and allows awareness of this management style is to encourage employees to be comfortable with diversity in the workplace and develop understanding of differences in race, gender, background, or any other factors that may not be shared by everyone working in the same area of the company.

The position of leader recognition and acceptance of diversity among the employees can convert a hostile workplace environment into a welcoming environment where people freely communicate and support one another with any tasks associated with the job. Its rationale reflects the fact that while there is considerable research on equity the implementation of a diversity leadership approach often makes it possible for productivity levels to increase dramatically. Diversity to explain all aspects in which people differ from one another. The perspective adopted to examine both the visible and relatively easily demonstrable personal characteristics such as gender, age and ethnicity, as well as the less visible personal characteristics, such as dominant the competencies, needs and wants, work styles and character traits. The context of each employee has his or her own, unique combination of such characteristics. Alternative characterization describes diversity as creating high performing organizations through valuing and using all the talents of employees of different groups. This view is shared by workplace diversity refers to the variety of differences between people in an organization. More exact successful organizations recognize the need for immediate action and are ready and willing to spend resources on managing diversity in the workplace now. The conceptualise leadership to embrace diversity may actively when their organizations handling of workplace diversity issues, develop, implement diversity plans, and multiple benefits are reported. Leadership focuses the encouragement in workplace that inspire all of their employees to perform to their highest ability. The intention is to stimulate reflection on how workplace strategies can then be executed, resulting in higher productivity, profit, and return on investment.

\section{ESSENTIAL OF THE LEADERSHIP COMPETENCIES}

By focusing on skill development and leadership competencies, an organization will be able to promote better leadership in their employees, and also is able to build future leaders from their current workforce. While the skills are critical to establishing a solid leader, different needs of an organization may call for requiring a different or additional skill set to meet the needs and business strategy of the organization. A creative leadership encompassing 


\section{SJIF Impact Factor 2021: 8.013| ISI I.F.Value:1.241| Journal DOI: 10.36713/epra2016 ISSN: 2455-7838(Online) EPRA International Journal of Research and Development (IJRD) Volume: 6 | Issue: 11 | November 2021 \\ - Peer Reviewed Journal}

various activities and experiences that enhances the ability to make a meaningful difference essential leadership skill. These may lead to success among a consistent number of organizations with breaks down leadership competencies in design primary categories, leading the organization, leading others in the organization, and leading the self.

i. Leading the Organization - To begin with leaders needs to be strong in the organizations evolve with the times, so does the leadership qualities, skills and capabilities of the people tasked with leading such organizations. To be effective, leadership is no longer about hierarchy and flexing muscles, but about creating relationships of mutual respect with employees. In an organization, leadership development programs bridge the gap between natural leadership traits and the specific needs of the organization. Ideally, it is imperative that leaders develop flattening organization structures, leadership is about team-based direction and embracing the collaborative mission-based teams. Learn effective strategies for developing, articulating, implementing organizational and alignment will lead to strengthened feelings of self-worth, which leads to self-confidence, employee engagement and high performance. Leaders should encourage their team with the tools and skills to do their jobs well. Excellent leaders are drivers of change who encourage creativity and innovation in the workplace. Implement be a successful leader that ability to solve problems, make decisions, manage changes, influence others, manage politics, innovate, take risks, establish the vision and strategies, manage the workplace effort and goals, and understand the navigation of the business. To accomplish the most organizations, need to build their leadership pipeline, out of their workforce, leaders of the organizations need to support their teams and ensure there is clear understanding, effectively with a feeling of appreciation and inclusiveness. On additional workplace environment demands that leaders have the requisite skills and capabilities that are fundamental to leading a modern organization effectively.

ii. Leading Others in the Organization - Leaders often need to learn to recognize their potential contributions and themselves as leaders, establishing a positive vision influencing employees to understand and accept the future state of the organization. Handle the variety of challenges that come their way with agility will influence the employees perform their duties by explaining the vision and the importance of their role in the outcome. Engage and empower employees to achieve extraordinary results by motivating and find out enough about the needs and wants of employees, giving them what they need and providing praise for a job well done. Understand themselves, the impact they make on others and communicate to learn more about their needs and wants. Use the right tools to take the reins in their development as leaders when guiding employees, it is important to define their role in the work process and participate in their efforts along the way. Strengthen their disposition to drive for results consistently, creating high quality performance, explain the tasks, provide the digging tools, direct the work and be available to assist the employee if they run into a problem. Increase self-awareness, personal agility, and courage everyone together to work towards a common goal. Develop the ability to engage, coach, and develop others be able to communicate effectively, value the diversity and maintain interpersonal relationships effectively manage the teams. Build understanding of the leadership behaviours that are critical to successful people who looking for leaders who can appreciate their vulnerability and inspire them, understand them, support them, and guide them through the looming chaos. Build understanding of the leadership behaviours that are critical to successful and timely manner, create conditions that foster trust.

iii. Leading Oneself - It defines the role of the leader and how this role works with others in the organisation. Successful leaders, create opportunities to coach team members on how to be more effective, outlines the knowledge, skills and behaviours required of all managerial leaders. It provides a toolkit of principles that leaders and teams can quickly use to address day-to-day challenges and development of team members follows naturally from effective task assignment and completion. Leaders must have a clear understanding of what each role is accountable to do and what authorities they have to do it. Therefore, understanding goes beyond the technical and programming aspects of a role and extends to the requirements of managing people. This may involve helping a team member to see better 
ways to solve problems, clearly defines the requirements for leadership, sets practical and consistent standards expected of leaders. It provides a toolkit of principles that leaderships and teams can quickly use to address day-to-day challenges. Determining performance improvement actions and simplifies leadership as something everyone can understand and contribute towards. Successful leaders build and lead an effective team so each member is fully committed and capable of moving in the direction set. Being able to lead oneself, it allows leader able to show demonstrated ethics and integrity while performing their job, know how to manage themselves, be able to increase selfawareness, develop adaptability, exhibit and accountability for employee development a leadership stature, and display drive and purpose.

Effective management and leadership are vital in these times of complexity and fast change in organizations, consider the competencies that the individual possesses and compare those to the ones that require to further develop for success in a leadership role. Leaders play a vital role in leading people through organizational change of his/her current competencies that allows the organization to meet its strategic goals. Leaders are someone who guides an organization and its people towards a future vision for the organization. They recognize the opportunities inherent in organizational change and makes things happen to realize that change. Ideally, they have integrity, credibility and trust of others in the organization move towards this organizational change. They proactively take steps to lead their group towards a vision of the future and they know that feedback is essential to their development competencies of knowledge, skills, and abilities that represent effective leadership within an organization. The usual method is to provide leadership competencies include social intelligence, conflict management, interpersonal skills, (learning) agility and decision-making. There's more to learning than knowing how to be a good coach, emotional intelligence, industry expertise, change management, sharing a compelling vision, courage, managing yourself, inclusiveness, organizational citizenship behaviour, and people management. The competencies of leadership are skills and attributes that can possess which make a good leader. The competency or ability to show, these skills will increase the trust and commitment that team has diversity leadership. They organize how an organization's work gets done and by whom inspire, encourage and facilitate in order to improve the productivity of their team.

\section{IMPORTANCE OF THE LEADERSHIP COMPETENCIES}

The exponential pace of change creates significant challenges to the development of new leaders that perform a competency in the field that make a valuable asset to the entire team. They motivate the way of leading should be flexible and adaptable to the context and the culture of the organization. More influential they use the strengths of the organizational culture in their efforts to implement change. They remain having the concept of knowledge, skills, competence and understanding of how to engage, motivate and manage people. What are the leadership best practices today?

Integrity - Leaders help identify strengths and development needs by providing a benchmark of how leaders doing as compared to a meaningful norm group. Integrity does the right things even when no one is watching. By evaluating leadership competencies and they also provide actionable insights to help build on these competencies to grow even more with the integrity, consistency of their character in both their personal and professional relationships. Leadership competencies have a clear sense of direction and are ready to take action, but need some help understanding of ideas for improving own integrity may include:

i. Upholding the values and beliefs of their organization, even when it is a challenge.

ii. Admitting their mistakes with an honest and humble attitude.

iii. Prioritizing honesty in all their professional dealings.

iv. Making sure all the professional decisions are in line with the values of the employer.

v. Doing everything and ensure the well-being of their customers, clients and employees

Self-discipline - The combined with many of these competencies require leaders to have the fundamental quality of self-discipline. Leaders consistent with their values act not out of their own interest, but out of a concern for others. One way to accomplish they carefully consider the possible consequences of their actions instead of making rash decisions. Envision a clear direction while allowing employees to organize their own time and work was identified as the next most important leadership competency. Decision making those who are closest to the action and selfdiscipline involves natural tendencies to act out of anger, greed or selfishness include:

i. Making aware of how decisions affect others.

ii. Choosing to prioritize the needs of others.

iii. Managing time carefully.

iv. Using energy wisely.

v. Making a commitment to self-improvement. 


\section{SJIF Impact Factor 2021: 8.013| ISI I.F.Value:1.241| Journal DOI: 10.36713/epra2016 ISSN: 2455-7838(Online) EPRA International Journal of Research and Development (IJRD)

Communication - Undertaking organization challenges in communication competency, which leaders enhance be prepared and positioned to further hone their skills amid transformation. Essentially the behaviours enhance a leader's performance are often evaluated their team's productivity. Communication based on leadership development method, enables companies to identify and improving productivity in the workplace. Adapting to evolve strategies, leaders' capabilities are willing to share their ideas and plans with their team. Hence, leaders demonstrate a tendency to internalize a learning mindset and always seek learning opportunities to complete their organization assignments if they have accurate and actionable information. Possesses the ability to be open to feedback and reflecting on past experiences to learn from successes and failures. Effective leaders are willing to listen to input and ideas from their teammates in a way help organization builds a sustainable element in communication. The courage to stay put and adapt to the changes is one of the most important leadership communications. The strategies to overcome their willingness of team members who see that their opinions, ideas are acknowledged, continually to trust their leader's decisions and judgment. Here are some suggestions for improving communication skills:

i. Make an effort to ask colleagues for their opinions and ideas.

ii. Deliver instructions clearly and thoroughly.

iii. After sharing information, ask listeners if they have any questions or concerns.

iv. Be open to considering others' points of view.

v. Maintain an atmosphere of openness in the workplace.

vi. Make it clear to them that their input is valuable.

Trustworthiness - Demonstrate a tendency to focus team members' professional growth and development by identifying their strengths and trust. Most organization operates based on established trust between employers, employees and consumers. Team members who work together will help to achieve organizational goals by maximizing output and productivity effectively. However, leaders need to develop team members to build trustworthiness to both superiors and team members. They identify the gaps, pose challenging tasks and drive them to achieve the targets in a pre-defined timeframe trustworthiness opportunities to succeed. The tendency to build trust with everyone in the workplace is an important part of being a competent leader. Implementing new ideas to create more efficient processes, products or improve experiences a steady business growth. Encourages the team to ideate and provides the necessary assistance by closely monitors the progress and offers constructive feedback by identifying blind spots and areas of improvement. This may help them troubleshoot and solve problems as needed also encourages coaching for professional development and improve trustworthiness:

i. Endeavor to always meet deadlines and turn in assignments on time.

ii. Work on delivering reliable and worthwhile results.

iii. Always follow through promises.

iv. Be forthcoming about mistakes.

v. Prioritize honesty in professional relationships and interactions.

Teamwork - Leaders can achieve several goals by establishing a robust to approach issues differently, thinking out-of-the-box and striving for continual innovation. Identify the valuable quality in a leader is their ability to be a team player. Building relationships with decision-makers in the organization develop open lines of communication that encourages people to innovate by experimenting and 'failing fast,' with new ideas and sharing their learnings across the organization. Optimally utilizes available resources and makes a special effort to devise new strategies, they know their team well enough to recognize their skills and know how to use them. Fosters a relationship of mutual trust, understanding, growth and learning, may formulate strategies to achieve the organizational vision and focus effectively execute the plan. Ideally, great leaders know when to move quickly and team players to make personal sacrifices in order to improve the overall productivity of the team. Follows a systematic approach in exploring new territories and exhibiting teamwork by prioritizing the good of the group over personal gain. The possibilities decision for how to improve the competency in teamwork include:

i. As a leader familiarize with team members' strengths and weaknesses.

ii. Volunteer to contribute to group projects or tasks.

iii. Be willing to support team in a new capacity.

iv. Be willing to adapt or change point of view.

v. Give others the chance to excel and show their skills.

Conflict management - It is also important to note that competent leaders know how to manage and reduce conflict in order to preserve a pleasant and productive work environment. Leaders must be able to utilize conflict management skills to provide direction and guidance towards a resolution because a skill full leader need to give priority to learning and mastering. Leaders must be able to adapt to different conflict management situations, and recognizing 


\section{SJIF Impact Factor 2021: 8.013| ISI I.F.Value:1.241| Journal DOI: 10.36713/epra2016 ISSN: 2455-7838(Online) EPRA International Journal of Research and Development (IJRD) Volume: 6 | Issue: 11 | November 2021 \\ - Peer Reviewed Journal}

which type to establish a foster teamwork adopted by the entire organization. One-way leaders can accomplish their goals is through by recognizing one's own leadership style will ultimately help describe how a leader handles conflict. Ultimately, conflict management must be a part of a leader's toolbox and be deployed when conflict arises within a team or organization. Leaders need to make sure that all team members understand how decisions will be made to resolve the conflict and they manage conflicts in a way that it is seen as an opportunity to build productive relationships.

i. Learn to sense tension workplace.

ii. Make sure employees know they are welcome to come directly with any complaints or dissatisfactions.

iii. Practice tact when offering advice or input on a situation.

iv. Negotiation skills or seek out opportunities to observe them in action.

Problem-solving - Implementing a solution and problem solving involve all the work that leaders must perform to reach the conclusions and judgments necessary for them to act in any situation. To solve a problem, first make a decision as to the approach to overcome the obstacle and achieve the objective, then determine how to carry out that decision. Look for overall patterns and ask questions about who, what, when, where, why and how to understand the scale of the impact. The objective is to find the root cause to allow to implement a permanent resolution instead of a temporary fix. Problem solving is best conducted when many people can contribute their best ideas, skills, and need to keep an open mind to hear from top talent and innovate ideas across the organization. Cultivating strong problem-solving skills is critical for leaders at any level career stage, and starting ensures as an advance. Part of problem-solving is knowing the ins and outs of career field, combine the knowledge of the job, practical experience and creative thinking to solve problems in the workplace include:

i. Studying the details of how the job, workplace and industry function.

ii. Seeking advice from senior professionals in the workplace.

iii. Logical thinking skills and how to implement them in the workplace.

iv. Learning from any mistakes might make while gaining experience.
Initiative - Leaders are versatile to authoritative figure that serves as a role model and directs the team. A combination of learning leadership skills in the workplace while practicing leadership qualities can teach how to be a good leader at work It should come as no surprise and part of being a good leader is the ability to take the lead. Leaders make the decisions, of which some take the steps necessary to fill it. Evaluate every option and make the right decision, they don't always wait to be asked before agreeing to manage or contribute to a task. It is important to motivate the entire team with encouragement and make their job enjoyable, so they look forward to coming in to work. Flexibility is key in keeping competent leaders use their initiative and innovation to produce valuable results and show initiative:

i. Look for needs in the workplace and think about how might be able to meet them.

ii. Volunteer to solve an inconvenience or inefficiency in the workplace.

iii. Go above and beyond the minimum requirements of a task whenever appropriate.

iv. Take it upon to do the necessary research before pitching an idea.

v. Tackle any problems that might appear with methods or plans instead of expecting someone else to solve them.

It's just as important to be wise in the way leadership initiative and make things happen are highly valued in the workplace, the ability becoming important. Flexibility and courage are what pushes teams and organizations to innovate are abandoning hands-on leadership styles to encourage their team members to "think on their feet," to be more agile and responsive, and to show more initiative. Consider their organization will develop a mutual, trusting relationships is important and become a more competent leader is an admirable aspiration for anyone who hopes to be a positive influence in their workplace. It contributes team members to feel that they contribute to the organization's mission by providing constructive feedback, and by engaging them in decision making. Develop a self-confidence leader can make all the difference in the organization, the competent leaders increase productivity, improve workplace morale and inspire their team. To improve existing setups and contribute new ideas may enhance an effort to improve their skills in the areas that can help become a more competent and efficient leader. The initiative a part of how the organization works the mixture of benefits from managing diversity includes procurement and retention. It can take courage and a strong sense of self to initiative teams take the initiative demonstrate better creativity, 
communication, decision making, trust, respect, and productivity.

\section{CHALLENGES OF DIVERSITY AT THE WORKPLACE}

The most challenging aspect of a diverse working environment is more than simply accepting acknowledging and embracing differences in people. Different perspectives, opinions, and ideas can lead to being more innovative and better problem solving perhaps, negative attitudes and behaviours can be barriers to organizational diversity that can harm relationships, work productivity and damage morale (Esty et al., 1995). Building an inclusive workplace can help the offended team member identify a misunderstanding and finally, leaders must be willing to change the organization if necessary (Koonce 2001). When people feel confident that their team members respect their differences, therefore organizations should identify how to manage diversity in the workplace to be successful in the future (Flagg 2002). An inclusive workplace will also create an environment in which team members welcome feedback, mainly depends on the leader's ability to understand what is best for the organization based on teamwork and the dynamics of the workplace. One of the ways that organizations can overcome this platform is by consume the teachable moments that may support each team member do their part to create a more comprehensive workplace, while expanding their own knowledge and understanding of other cultures. As such formulate a space for this to happen by allowing more time for teams to consider different ideas, debate them, and come to more informed decisions. It is natural to let people raise their concern and there are always exceptions to the rule managing diversity more than an equal employment opportunity also affirmative action (Losyk 1996). Focus on what will impact the most people, there should always be a final decision maker who can take all ideas into consideration and decide how to ultimately move forward.

This is an important assignment that can acknowledge and recognize contributors to ensure other team members feel valued for their ideas. The process led them to identify full advantage of workplace diversity with facing many challenges such as communication barriers due to differences in perception, cultural background, language differences and reduced morale. An inclusive workplace may mean something different to everyone, leaders must know how to motivate and lead the diversified employees, coming from different cultural backgrounds carrying within them different expectations, different behavioural pattern, attitudinal differences and semantic barriers. The transformation of decision-makers must be aware of the potential issues they face so that they can be prepared with strategies to combat against them and ensure diversity initiatives take account. Understanding, with some of progression issues that stem from diversity in the workplace is to review existing company policies, training, develop and implement new ones that are relevant to the specific issues at hand, if needed. Despite various trends enhance leaders establish a culture of acceptance within an organization. Also, initiative a diversityrelated that integrated into an organization's mission statement and onboarding process. It is creating a particular challenge for employees to mentor one another, collaborate and engage daily on different projects is another great way to help bridge the gap besides help them to establish relationships.

\section{MOTIVATING AND LEADING DIVERSIFIED IN THE WORKPLACE}

Motivation can be a fluctuating feeling that many employees face throughout their careers and managing people is always a challenging issue for leaders working with diversified workplace. Managing requires leaders to recognize the ways in which the workplace is changing and evolving. Whereby managing diversity is a significant organizational challenge, so leader skills must adapt to accommodate a multicultural work environment. An understanding of motivation and how an employee is motivated is probably one of the most puzzling relevant tools that will help them complete their tasks more seamlessly. The definition of leadership is to inspire, energized followers when it comes to meaningful work. Hence, it motivates people highly adaptable, particularly when it comes to change, and they have a positive attitude at work. On the other hand, leadership's function is to enable change and establish detailed steps that allow employees to complete the task in a better standard within the organization's, reduce rates of absenteeism, improve performance and profit. Ideally, craft specific targets motivate people in a positive outlook and usually use to tailor the approach to motivation and not all are completely consistent with one another. It allows framing the strategy in multiple ways, ensures each member of the team has a clear understanding of how working together benefits them. It clarifies the relationship between effort and outcome, management should engage with employees during one-on-one checkins to get a deeper understanding to go the extra mile, their personal growth goals are, and what ideas they may have in the organization. This will allow greater insight into how leader can effectively lead the team based on their individual identity. Let employees' 


\section{SJIF Impact Factor 2021: 8.013| ISI I.F.Value:1.241| Journal DOI: 10.36713/epra2016 ISSN: 2455-7838(Online) EPRA International Journal of Research and Development (IJRD) Volume: 6 | Issue: 11 | November 2021 \\ - Peer Reviewed Journal}

shape the leadership style know about workforce more effectively can lead them to success. The new strategy inspires important task to keep employee engagement, productivity and high motivation. The processes, reduce the boredom and repetitiveness of the job, while a challenging task can give the employee a sense of importance that will make them feel valued within the organization. Well, there are 6 key considerations may want to pay close attention to:

i. Increase levels of communication and use internal platforms.

ii. Set out clear expectations and give them goals.

iii. Encourage them to keep learning and up skilling.

iv. Recognise their efforts and regularly praise stand-out performers.

v. Offer guidance on how best they can manage their time.

vi. Arrange for the more senior team members to act as mentors.

\section{WAYS TO IMPROVE THE LEADERSHIP SKILLS}

Leadership is the process of motivating an individual and others to work towards achieving a specific vision, inclusive career development is borne in mind and leadership skills have a groovy role to play in it. However, the truth is that anyone can develop the skills needed for a leadership role, but the important way to improve leadership skills and technical skills would be able to take a sealed point that can forge as a good leader. Although it will take some practice, to get better job positions and become more successful like smashing heights in career, leadership traits, managing conflict and building a good team employed or boosted to higher levels in professional life. The quality of leadership skills that helps in organizing and leading the team to work their best as required and also monitors them effectively for the growth of the organization. It's also very important to learn leadership skills that not only employers, but every employee should possess. Leadership provides direction and qualities, skills that can be improved through continuous practice and purposefully working towards building expertise in a particular area, subject or profession. Keep in mind, leadership skills can be developed through practice, proper implementation, and monitoring better outcomes also including below ways on how to improve leadership skills in the workplace:

Being Decisive - One of the qualities of a good leader is the ability to be decisive, it can be tempting to shy away from making decisions, especially when don't have sufficient information or when the outcome can be unfavourable. An initial step on the path towards becoming a great leader is their ability to make timely decisions with circumstances where their decisions will be good and in other instances decisions would be bad. Keep working on decision making skills so that as leader will get more comfortable being decisive and over time aim to make better decisions than bad ones. In the event that a decision made turns out to be unfavourable, use it as a learning opportunity and identify lessons learned that can help to improve future decisions.

Practice Communicating Well - Leaders are constantly to have a good practice of communication skills will serve well, especially in sharing vision with others. Poor communication and lack of communication are barriers to effective leadership. Identify quality of communication is part of important things when sharing information from one person to another. Specifically, the benefits of clear communication include strengthening work relationships, increasing productivity and collaboration, prioritizing well, increased work satisfaction and saving time and money. Whereby, effects poor communication consist lack of clarity on which direction to follow, confusion where people are unsure of what they are supposed to be doing, tension at work, low morale, stress and gossiping in the absence of information. Manage simple ways of practicing good communication skills entail sharing information, offering clear instructions, clarifying, following up, being available to answer questions, providing regular updates and feedback.

Delegate Effectively - There are many members who look at their inspired leaders and emulate their behaviours actual fact is that leaders can't possibly do everything by themselves, hence the need and importance of redistributing work and achieving results through others. A true leader should recognize the problem and assignment should not be used as a tool for dumping unpleasant tasks to employees rather it should be viewed ideas that were effective with new ways of handling tasks and work for its success and giving subordinates a chance to try their hand on new tasks and responsibilities. An optimistic attitude is another quality which helps in improving the leadership quality also a strategic tool to help leaders timely measure an important priority and also manage their team members. Being confident and thinking positively will motivate them in a positive way when handed over tasks to subordinates, ensure that give clear instructions on what the final output results, desire to enhance leadership skills be available to answer any questions or provide clarifications as needed. Brighten path for the team to follow, leaders is apprehensive about delegating because of reasons such as wanting to do all the work 
by themselves. In directly not believing that others can execute tasks, unwilling to commit the time involved in training someone on a new task, and fear that employees might do a better job than them and outshine the leader. By delegating tasks gain time to focus on goals which are to be accomplished as employees get used to being trusted with more challenging responsibilities, this can help to motivate them and increase their job skills. Courage is mandatory for a leader creates a path towards a job promotion whereas an employee accomplishes progressively challenging responsibilities, they in essence demonstrate that they are capable of desiring to enhance leadership skills performing at a higher level than their current position.

\section{RECOMMENDATION}

Organisations may at times have a full-fledged workplace to individual and organization success. The organisation should be willing to challenge and change practices that be perceived as barriers to different groups. Another important way to ensure diversity, inclusion to make the workplace approach towards building a diverse team. Ensure that the selection process is free who feels respected and accepted by management is more likely to churn out better work, have solid workplace relationships and engage in more leadership roles. With the growing diversity, an organisation needs to ensure that the overall recommended steps that have been proven successful in world-class organizations are:

i. Measurement of diversity in the workplace makes assessing and evaluating their diversity process an integral part of their management system. Employee accomplishes this assessment for efficiently and conveniently. The way, creating a huge element of this understanding can help management teams determine which challenges and obstacles to diversity are present in the workplace and which policies need to be added or eliminated.

ii. Development of diversity in the workplace plan, choosing a comprehensive key decision that reportedly will be the beginning structure of diversity in the workplace plan. The plan must be comprehensive, attainable and measurable in an organization to decide what changes need to be made and a timeline for that change to be attained.

iii. Increase Adaptability Accomplishment of diversity in the workplace plan incorporates diversity policies into every aspect of the organization's function and purpose. Ensure better understanding of employee requirements and demands leading finally to better decisions. Facilitate an employer brand that is seen as inclusive, thus becoming an aspiring organisation for top talent. While diversity provides many benefits to the organisation understanding in managing management cooperation and participation is required to create a culture conducive to the success of the organization's plan.

iv. The most positive effects of diversity are the boost it provides to innovation in the workplace. The diversity increases the innovation and creativity at work encourages employees to learn from others and share ideas by brainstorming and sharing experiences. Take steps and initiatives to encourage employee turnover in the workplace more receptive to trying out new things, thus increasing the innovation and creativity at work.

\section{CONCLUSION}

In summary, the aim of this research is to identify the role of leadership can work in different capacities, yet be the same when developing an organization. In providing clarity to teams, leadership is nothing if it doesn't build a system-based management structure, and management would have no support without the work of leadership as the backbone of ideals. Specifically, in trying to fix the leadership challenges of understand the important leadership style chosen, it has to relate to inherent beliefs. Essentially, it is shaped and cultivated throughout life through natural, social occurrences, assumptions, and inherent beliefs. The availability of important growth for leaders is to find their own selfreflect on what their beliefs mean to their leadership styles and how they develop their leadership strategies. As prospective leaders, it is highly important to locate and cultivate a personal leadership style to become successful in a future workplace. In order to succeed and with the execution at all levels of the organization, the messaging of the vision or strategic objective, everyone will be more open-minded with their coworkers. Also, having diversity workers benefits the company because they could be the ones to make positive ties with other companies and bring in new customers. When strive to improve leadership skills, leaders shaped into a more valuable employee, such as human leader necessitate empathy, positivity, compassion, purpose, humility, and love. All these key traits will help travel down the genuine path with team members. Now is a good time to conduct a 


\section{SJIF Impact Factor 2021: 8.013| ISI I.F.Value:1.241| Journal DOI: 10.36713/epra2016 ISSN: 2455-7838(Online) EPRA International Journal of Research and Development (IJRD) Volume: 6 | Issue: 11 | November 2021

\author{
- Peer Reviewed Journal
}

leadership suitability to being a responsible for the action and direction of the team is a perfect leader to achieve organizational goals is important. To get everything perfectly right the valuable points would be of great assistance to improve leadership skills.

\section{REFERENCES}

1. Adams, J.S. (1965), 'Inequity in social exchange, In L. Berkowitz (Ed.)', Advance in experimental social psychology, vol.2, pp. 267-299. New York: Academic Press.

2. Alder, N.J. and Bartholomew, S. (1992), 'Managing globally competent people', Academy of Management Executive, Vol.6, pp. 52- 65.

3. Ayman, R., Kreicker, N.A. and Masztal, J.J. (1994), 'Defining global leadership in business environment', Consulting Psychology Journal, Vol.46, pp. 64-73.

4. Bhagat, R.S. and McQuaid, S.J. (1982), 'Role of subjective culture in organizations: A Review and directions for future research', Journal of Applied Psychology, Vol.67, pp. 653-685.

5. Bracey, H., Rosenblum, J., Sanford, A., \& Trueblood, R. (1990). Managing from the heart. Atlanta: Heart Enterprises.

6. Bruce D. Schneider (2008). Energy Leadership; Transforming Your Workplace and Your Life from the Core. Hoboken, NJ: John Wiley \& Sons, Inc.

7. Covey, S.R. (1989). The 7 habits of highly effective people: Powerful lessons in personal change. New York: Simon \& Shuster.

8. Esty, K., R. Griffin, and M. Schorr-Hirsh. 1995. Workplace diversity. A manager's guide to solving problems and turning diversity into a competitive advantage. Avon, MA: Adams Media Corporation.

9. Flagg, A. 2002. Managing diverse workgroups successfully. United Behavioral Health.

10. Goldhaber, G.M. (1993). Organizational communication (6th ed.). Boston: McGraw-Hill.

11. Kanungo, R.N. and Wright, R. W. (1983), 'a cross culture comparative study of managerial job attitudes', Journal of International Business study, Vol.14, pp. 115-129.

12. Koonce, R. 2001. Redefining diversity: It's not just the right thing to do; it also makes good business sense. Training and Development (December).

13. Kostera, M., Proppe, M. and Szatkowski, M. (1995), 'Staging the new romantic heroin in the old cynical theatre: On managers, roles and change in Poland', Journal of organizational Behavior, Vol.16, pp. 631-646.

14. Loysk, B. 1996. Managing a changing workforce: Achieving outstanding service with today's employees. Davie, FL: Workplace Trends Publishing.

15. Rodrigues, C. (1990), 'The situational and national culture as contingencies for leadership behavior: Two conceptual Models', In B. Prasad
$(E d)$, Advances in international comparative management, Vol. 5, pp. 51-68. Greenwich, CT: JAI Press.

16. Robinson, K-S. 2002. U.S. must focus on diversity or face decline in competitiveness. The Society for Human Resource Management (SHRM).

17. Shaban, A. (2016), 'Managing and Leading a Diverse Workforce: One of the Main Challenges in Management', Procedia - Social and Behavioral Sciences 230, pp. $76-84$.

18. Shapiro, P. (2005). Too many leaders? or do we use the term "leader" too freely? News \& Tools Leadership, 1(2), 1-2.

19. Wergin, J.F. (2007) (Ed.). Leadership in place: How academic professionals can find their leadership voice. Boston:Anker. 